\title{
"Patterns of Distress, Precipitating Events, and Reflections on Suicide Attempts by Young Latinas"
}

\author{
Luis H. Zayas, PhD, \\ Washington University in St. Louis, Saint Louis, MO UNITED STATES \\ Lauren E Gulbas, PhD, \\ Washington University in St. Louis
}

Nicole Fedoravicius, MPH, and

Washington University in St. Louis

Leopoldo J Cabassa, PhD

Columbia University

\begin{abstract}
By most epidemiological accounts, young US Latinas attempt suicide more often than other youth. Little is known, however, about the circumstance and internal experiences of the attempts. To understand this phenomenon, we conducted thematic analyses of twenty-seven qualitative interviews with teenage Latinas (aged 11-19) living in New York City who had attempted suicide. Collected between July 2005 and July 2009, the interviews explored the emotional, cognitive and physical experiences of the attempts and the social situations in which they took place. Results show that the girls were divisible nearly equally into a group with a stated intent of death and a group that did not intend death. The pathways to the suicidal event consisted of a pattern of continuous, escalating stress (primarily at home) that created the emotionally combustible conditions for the attempt. A trigger event that either reminded them of past stress or revived feelings of that stress catalyzed the attempt. Guilt and remorse were common responses to the suicide attempts, and on reflection the girls demonstrated some broader perspectives. Results of the analysis clarify the sociocultural context of the suicide attempts, underscoring the cultural discontinuity experienced by adolescent Latinas, who struggle to reconcile traditional Hispanic gender socialization with their own insertion in a modern Western society.
\end{abstract}

\section{Keywords}

Latinas/Hispanic females; adolescents; suicide attempts; USA; culture; ethnicity

\section{Introduction}

For at least two decades, epidemiological research has confirmed the high rate of suicidal behaviors by pre-adolescent and adolescent females of Hispanic origin (i.e., foreign-born) or

(C) 2010 Elsevier Ltd. All rights reserved.

Corresponding Author: 1zayas@wustl.edu.

Publisher's Disclaimer: This is a PDF file of an unedited manuscript that has been accepted for publication. As a service to our customers we are providing this early version of the manuscript. The manuscript will undergo copyediting, typesetting, and review of the resulting proof before it is published in its final citable form. Please note that during the production process errorsmaybe discovered which could affect the content, and all legal disclaimers that apply to the journal pertain. 
heritage (i.e., U.S.-born; Centers for Disease Control and Prevention [CDC], 2008; Substance Abuse and Mental Health Services Administration [SAMHSA], 2003). Surveys that include youth in middle school (ages 11-13) and/or high school (ages 14-18) show that Latinas are at higher risk for suicidal behaviors than other ethnic and racial groups in American society. National surveys of adult Hispanics also report that suicide attempts are more likely to occur before the age of 18 (Fortuna, Perez, Canino, Sribney, \& Alegría, 2007). Furthermore, the prevalence of suicide attempts among young Latinas has not been confined to one Hispanic subgroup (We use the term Hispanic for the broad population group in the U.S. that is traced to Spanish-language, Latin American origin. We use Latina to refer to Hispanic females).

Higher than average rates of suicide attempts have been reported on U.S. Latinas of Colombian, Cuban, Dominican, Ecuadoran, Mexican, Nicaraguan and Puerto Rican origin (Fortuna et al., 2007; Garcia, Skay, Sieving, Naughton, \& Bearinger, 2008; Garofalo et al., 1999; Rew et al., 2001; Tortolero \& Roberts, 2001; Zayas, Bright, Alvarez-Sanchez, \& Cabassa, 2008).

The first reports touching on this phenomenon were authored by Trautman (1961a,b) on a group of low-income Puerto Rican women living in a Hispanic enclave of New York City, the south Bronx. In his accounts, Trautman notes that the typical age profile of this group is young (mostly in their twenties). He describes the attempts as impulsive, usually carried out by ingesting prescription medications, over-the-counter pills, or harmful household substances, such as detergents. Trautman reports that women had no thought or intent of dying and generally did not show any severe mental illness or psychotic symptoms. Rather, the attempts represented escapes from stressful situations. The most commonly reported precipitant was an intense, stressful conflict, argument or fight with the women's mothers or spouses. For a period of nearly 30 years, the literature fell silent on the phenomenology of suicide attempts by Latinas, save for some theoretical speculations based on clinical experiences and feminist psychology (e.g., Zimmerman, 1991;Zimmerman \& Zayas, 1995).

Beginning in the 1980s, there was a resurgence of interest in understanding suicide attempts within Latina populations. Researchers have discerned, in agreement with Trautman (1961a,b), that family conflicts or disruptions, especially with parents or spouses, often trigger the suicide attempt. Cumulative stress in families appears to be a common factor in suicide attempts (Marttunen et al., 1993, 1994; Moscicki, 1999; Wagner, 1997) and particularly in Hispanic female samples (Berne, 1983). However, family discord is not sufficient to demonstrate a causal link: most young Latinas experience conflict within the family, but few become suicidal. As a result, many scholars have focused their attention upon the relationships between Latina suicide attempters and their parents. Razin and his colleagues (1991) found that mother-daughter relations are often weak, sometimes with socially isolated mothers who are emotionally dependent on their daughters. Herrera, Dahlbom, Dahlgren, and Kullgren (2006) and Zayas et al. (2008) also report that mother-daughter relationships of attempters are low in communication, mentoring, and emotional attunement; fathers are often absent emotionally or physically. Garcia et al. (2008) also found that emotional distress and suicidality among Hispanic high school students were highly correlated to the adolescents' perceptions of the availability of parents to communicate with them and to express caring. The tenuous relationship between attempters and their parents, and the women's often poor coping skills (e.g., withdrawal, wishful-thinking, passive rather than proactive tactics; Turner, Kaplan, Zayas, \& Ross, 2002) suggests that psychosocial functioning plays a large role.

A major shortcoming of this scholarship is the failure to acknowledge the importance of the sociocultural context. Clearly, reasons for engaging in self-injurious behavior result from a complex interaction between individual and psychological factors, on one hand, and social, economic, and cultural issues on the other. It is important to delineate the broader socio-cultural context within which Latina suicide attempts occur. 
Despite their growth to become the largest and most diverse ethnic minority in the U.S. at $15 \%$ of the total population (U.S. Census Bureau, 2008a), Hispanics remain in a disadvantaged position, experiencing high levels of poverty and low levels of employment and health insurance (U.S. Census Bureau, 2008b). With poverty come the attendant social conditions that marginalize a large number of Hispanic youth: substandard housing; crowded, inadequate schools; adolescent pregnancy, parenthood, and child welfare involvement; high rates of drugs and alcohol use in their communities; criminal victimization and profiling by law enforcement; and few employment opportunities for young men and women (Bourgois, 2002; LeBlanc, 2004). Some youth feel locked into barrios from which escape is difficult, for they have witnessed countless others who have found few ways out. The young Latina may see glimmers of hope, an alienating experience where "one must always walk alone, at one's own pace, and only after burying a part of one's soul" (Ojito, 2005, p. 221).

The experience of social marginalization is particularly acute for U.S.-raised children of Spanish-speaking immigrants, such as Latina adolescents. They have often "grown up between two cultures, belonging to both and to neither of them" (Itzigsohn \& Dore-Cabral, 2001, p. 319). Among parents, the traditional Hispanic emphasis on familism places the family first, ahead of individual needs. These are deep obligations, emotional compromisos (commitments) and loyalty that require sacrifice for the family (Kao et al., 2007). This contrasts strongly with traditional Western values that prioritize individualism and independence (Lester, 2007). Complicating these cultural contradictions, indeed discontinuities, are the two competing socialization models for women's identities. Although the paradigm of machismo, which emphasizes male domination and female subordination, has been weakened somewhat, it continues to have significant cultural capital within Hispanic populations (Ascensio, 1999; Chant, 2003; Nencel, 2000). Similarly, modern feminism has weakened traditional gender roles, transforming women's positions of passivity and dependence toward roles that include will, assertiveness, and strength (Bordo, 1990). In this way, being a Latina daughter of immigrant parents represents a liminal space (Turner, 1969)—a developmental point in which she is neither a traditional Hispanic woman nor a modern mainstream woman, neither a child nor an adult. The young Latina finds herself "betwixt and between assigned cultural positions" (Gutmann, 1996, p. 31). Latinas must learn to negotiate their everyday actions of respectful deference on one side and autonomy on the other side, and often without the mentoring by more experienced adults who have resolved the cultural discontinuities in their own lives. Within this economic and political context, the young Latina must also negotiate two cultures as she grows: the one at home and the one outside.

A study by Taylor, Veloria, and Verba (2007) explores this cultural discontinuity in the words of a group of Latinas in high school, mostly Dominicans. These young women must deal with, on the one hand, parents' traditional customs, views and values, including the preferential treatment of men in their families. On the other hand, outside the home the girls encounter a culture based on a middle-class Western culture that encourages women's autonomy and selfinterest, features needed to manage social mobility. Taylor et al. (2007) note that the young women's relationships with mothers, fathers and brothers occur "against a backdrop of protectiveness and restricted freedom" (p. 162).

It is precisely within this cultural and developmental node that our study is situated. In this paper, we report on a study exploring the experiences of a group of young Latinas in New York City who had attempted suicide at least once and possibly more in their lifetimes. Our primary research questions in this report are: What are the conditions in which suicide attempts occur among young Latinas? How do Latinas experience the circumstances that led to the attempt? What do the young women say precipitated their suicide attempts and what triggers the act? 


\section{Method}

In a large federally funded study of the sociocultural process of suicide attempts among young Latinas conducted between July 2005 and July 2009, we designed a mixed-method, multiinformant study using stratified purposive sampling (Kemper, Stringfield, \& Teddlie, 2003; Patton, 1990), intentionally selecting adolescent Latinas who had attempted suicide and a comparison group that had not in order to obtain information-rich cases for close scrutiny. The overarching aim of the project was to understand the suicidal experience of Latinas in the second decade of life. The respective institutional IRBs at which this study was undertaken approved the study. All responsible human research ethics were followed.

\section{Participants}

Eligible participants were Latinas between the ages of 11 and 19 from the boroughs of Brooklyn, The Bronx, and Manhattan of New York City, communities with large concentrations of Hispanics. In fact, over half of our sample lives in communities and neighborhoods where the Hispanics make up between $50 \%$ and $80 \%$ of the population, and the majority live in areas where more than 1 in 3 families live below the federal poverty line. The age range we selected is one commonly used in national surveys of youth (CDC, 2008; SAMHSA, 2003). Our study group was comprised of self-identified Latina teenagers who had attempted suicide and who were cleared by therapists to participate in the study. These girls were recruited from a large social service and mental health agency and from psychiatric outpatient, inpatient and emergency services of several hospitals. A suicide attempt was defined as any intentional non-fatal self-injury, no matter how medically lethal, if the girl admitted it at the time immediately following the attempt, usually to a clinician, a friend, or teacher (O'Carroll et al., 1996; Silverman, Berman, Sanddal, O'Carroll, \& Joiner, 2007). More specifically, in accordance with contemporary nomenclature (Silverman et al., 2007), we consider a suicide attempt as a self-inflicted, potentially injurious behavior with a nonfatal outcome for which there is evidence (either explicit or implicit) of intent to die. Recognizing that a suicide attempt may or may not result in injuries to the person (or result in death), we included girls for whom suicidal intent was detected by others or the girls reported suicidal intent. This approach, thus, included Type I (no injury) and Type II (with injury) suicide attempts (Silverman et al., 2007). We did not control for degree of lethality of attempts.

Excluded were girls who were outside the age range, diagnosed with mental retardation or major mental illness, or placed in foster care at the time of the suicide attempt. Treating clinicians assessed each girl for capacity to participate to avoid imminent risk or psychologically fragile participants. Adolescents provided assent and consent, and parents also consented to daughters' participation. Procedures used in this study were approved by the Human Research Protections Office of Washington University in St. Louis and each of the participating agencies and hospitals.

With this purposive approach, we recruited 122 young Latinas receiving services at recruitment sites, a non-random selection. Of this group, $72(60 \%)$ were invited to participate in in-depth interviews to gather additional qualitative data that would provide insights into the suicide attempts. Our original plan was to collect in-depth interviews from 50 of the first 100 girls (every second girl). However, we decided that cases in which fathers participated would be automatically included in the qualitative portion of the study. With this approach (and sufficient funding), we exceeded our 50\% goal. The 27 interviews used in this report were conducted in the early stages of the qualitative portion of our study and were selected by the investigators on the basis of the richness of descriptions of the suicide attempts (see Table 1).

These 27 girls were on average 15 years of age and in ninth grade. They did not differ significantly from the remaining sample of attempters $(n=95)$ in any other demographic 
variables, save for a more even distribution of Hispanic groups in the subsample compared to the larger group which was mostly Dominican and Puerto Rican. Most girls in our subsample (74\%) were born in the U.S. or Puerto Rico, a U.S. territory. Interviews of these 27 girls were conducted on average 7.8 weeks (range 2 to 26 weeks) following the last reported suicide attempt. The most common methods for attempting suicide were cutting using an array of objects (e.g., knifes, pieces of glass, nail files) and overdosing with over the counter or prescribed medications. A small group reported using more than one method (e.g., cutting and trying to jump out of a building) during their attempts. Most girls had attempted suicide more than once $(n=21)$.

\section{Interviews}

In all cases, girls first completed the questionnaires that asked about the number and nature of attempts. The most recent attempt was used as the reference or index attempt for the in-depth interview. Interviews started with broad, non-threatening questions followed by more specific, sensitive topics (Charmaz, 2003; Smith \& Osborn, 2003), to elicit as much description and insight as could be recalled, articulated, perceived, understood, and explained by girls. We sought meanings, motivations, sensations, perceived causes, and internal experiences in the attempts, all from the girl's perspective. Girls were asked about social, emotional, physical/ somatic, psychological, and interpersonal experiences they had prior to, during and subsequent to the suicide attempt, including what words were said by whom, what states of consciousness the girls experienced, and what impulses they felt at the time.

The interviews covered family life (e.g., relationships with parents, siblings; discipline; conflicts, conflict resolution) and life outside the family and home (e.g., social network, extracurricular school activities, future plans, boyfriends or girlfriends, dating). These topics set the stage for exploring suicidal incident. Interviewers used whatever term the girl used for the incident and avoided introducing their own terminology. Such references as "suicide attempt," "cutting," "the incident," "that moment," were provided by the girls and these guided the interviews. The suicidal incident portion of the interview explored what happened to her; what was going on the day of the incident; how she decided to use the (pills, razor, etc.); what she was thinking and feeling during this time; what led her to make the attempt; what was going on right before the incident and what triggered her action; how close or distant physically was she from other people; and where she was and what she was doing when she made the attempt. Interviewers asked a girl to detail the very moment she was making the attempt; what her body felt like; how she felt or what she was thinking about; at what point she knew what was happening to her; and what happened to her after the attempt. Girls were asked to share their perspectives on the attempts and why they thought they did it. The interview often ended by asking participants to add anything else about the attempt that had not been covered.

Interviews were conducted by six trained bilingual Latinas who were master's degree level social workers or doctoral psychologists. Five of the interviewers were free-lancers and one was a full-time staff member who supervised the interviewers and ultimately conducted most of interviews (68\%). Our interviewers were trained to encourage participants to talk freely and spontaneously about the attempts and surrounding issues, to search for contexts, elements, patterns, and process. Audio-recording increased what Maxwell (1992) terms descriptive validity (i.e., factual accuracy of participants' accounts). Most interviews required about fifty minutes. Girls were paid for participating.

\section{Data Analysis}

Our analytic strategy required a continuous shifting between individual case and comparison across cases. Following the procedures outlined by Ayres and colleagues (2003), three investigators read each transcript independently for a general sense of the suicide attempt as 
described by participants. Then, transcripts were coded for general themes: precipitating events and factors; triggers, or events directly preceding the attempt; emotions and feelings prior to and during the attempt; and reflections on the attempt. Investigators compared codings, discussed disagreements, and retained coded segments if all investigators agreed. Statements of text that related to each of these themes were extracted and imported into a conceptual cluster matrix (Miles \& Huberman, 1994). The matrix was reviewed and revised during team meetings. The purpose of the matrix was to compare themes across all cases in order to identify experiences, events, and factors that were common to accounts of the suicide attempt. The matrix display contained reduced data (i.e., segments of text, phrases, quotations) and was organized by themes (columns) and individual accounts (rows), allowing the dataset to be seen as a whole. We could then identify groups of girls who had similar patterns of themes. From this, the research team returned to transcripts to compare individual accounts with other cases that possessed similar thematic configurations and also to account for irregular patterns or negative cases.

\section{Results}

\section{Ranges of Intent: Why They Attempted}

The intent of the suicide attempt was specifically discussed during interviews and our analyses indicate considerable variation in girls' descriptions of their intent. Utilizing the girls' own words, we identified three different kinds of intent: (1) death, (2) management of emotions, and (3) ambivalence.

The first group $(\mathrm{n}=12)$ verbalized a clear intent of dying, and they rationalized their actions by their wish to kill themselves. The desire to die was strongly linked to the emotional state prior to the attempt. Girls described feeling depressed, sad, lonely, guilty, and unworthy. The experience of emotional despair seemed to justify — to the girl—a desire to end her life. The method of attempting varied between cutting $(n=5)$, ingesting pills or another substance $(n=$ $5)$, multiple methods $(n=1)$, and suffocation $(n=1)$. But the common link within this group was that in the experience of solitude and sadness, suicide was perceived as the only option. As a 16-year-old Ecuadoran girl who attempted suicide by ingesting bleach described, "I did not want to live anymore. No one valued me. Because I felt that the whole world hated me, nobody loved me, so why am I here in this world?"1

The second group $(n=13)$ reported no intention of killing themselves. Rather, their actions represented a way to manage the overwhelming, and often conflicting, emotions present at the time. Girls described feelings of anger, hatred, frustration, sadness, stress, and confusion. Unlike Group 1, emotions such as "feeling depressed" or "feeling down" were absent, and anger appeared to dominate. Girls' related how their anger and frustration continued to build and escalate to the point where they needed to find a way escape or try to control these common stressors. Unable to rid themselves of these emotions or find tangible solutions to ongoing problems, girls reported how they turned inward and engaged in self-injury as a way to cope and control their feelings and emotions. Four girls ingested pills to manage their emotions, to induce a state of relaxation. Yet the majority of girls cut themselves $(n=8)$ using knives, razorblades, or other easily available sharp utensils to provide a physical release to an emotional state. A 14-year-old girl Honduran who cut herself with a math compass said of her internal experience

\footnotetext{
1“No quería existir ya ... nada me valía porque me sentía como todo el mundo me odia, nadie me quiere, ¿por qué estoy aquí en este mundo?"
} 
I feel like all the emotions are bottled up inside me. And I'm just, I need like some way to release it. Cause I didn't really know any other way to do it. And so that's like the only way I found. Right after, I'm released. I've been set free.

The third group was comprised of two girls who were unsure of the intent of their own actions. While both girls attempted suicide through cutting, neither girl experienced similar emotions during the attempt. One girl manifested emotions similar to Group1 (i.e., loneliness, guilt), whereas the other described her emotional state in terms similar to both Groups 1 and 2 (i.e., stressed, anger, feeling down). However, neither was able to articulate the purpose of attempting suicide, rather their intent was described in terms of ambivalence: "I don't want to say that I didn't want to kill myself, but I don't want to say that I did. I kind of have mixed feelings" (12-year-old, Dominican, cut self with razor blade).

\section{Patterns of Distress: Escalating Tensions and a Trigger}

The suicide attempt is usually preceded by a trigger that activates an overwhelming rush of emotions. The trigger is often a fight with a parent, usually the mother, but it can also come about as the result of a fight or conflict with siblings, other family members, or peers. We point out, however, that the presence of a trigger is not sufficient for understanding why girls attempt suicide. Rather, the trigger is an incident that occurs within the context of an ongoing pattern of instability and tension in girls' lives. This trigger stems from a unique moment-or a series of related moments—in a girl's life during which she felt particularly vulnerable, unprotected, or violated. The emotional repercussions of this moment persist, and the trigger often causes the girl to relive such moments. In this way, a single, painful moment in the girl's life can lead to a pattern of distress. These "patterns of distress" can be categorized into four main sources: changes in family structure, parental conflict, physical or sexual abuse, and bullying by peers.

For a number of girls $(\mathrm{n}=8)$, the source came from a sense of loss following a disruption in their family structure. The girls' families appeared to be in various stages of change, in flux, such as due to divorce, migration, or death; but the result of such change led to overwhelming feelings of loneliness. They felt bereft, adrift without the presence of persons who provided anchors, even if not the most stable ones in their lives. The sudden absence of a family member forced girls to try and renegotiate their customary systems of support within the family, but usually without success. Unable to regain stability, girls utilized their body as a vehicle to end the pain. An 18-year-old Puerto Rican attempter described, "My father died before I came here [to the US]. I guess I was my father's darling baby girl. His death really hurt me. Really, it made me cut myself. I think I really just felt very alone."

Conflicts with parents were another central and common source of distress. The subject of the conflict usually revolved around the failure to uphold household rules or responsibilities. These conflicts seemed to derive when girls exhibited an increased desire for autonomy, but parents remained inflexible and unwavering in their demand for control. Thus, the conflicts rarely resulted in a positive or productive outcome. It was not the conflict with parents that shaped girls' decisions to attempt suicide. Rather the conflict was embedded in a patterned social interaction that existed between girls and parents, most often their mothers. Frequently, this pattern of parent-daughter interaction made the girls the victims of verbal and emotional abuse, called "stupid," "worthless," or "whore" by their parents. Girls described being repeatedly degraded by their parents, causing them to feel unloved or angry. As conflicts continued, the internalization of this abuse often influenced girls' decisions to attempt suicide. A 13-year-old Ecuadoran girl who had cut herself with a knife described her relationship with her mother, "My mother when she gets angry tells me, 'I don't want to see you, I hate you, I hate you, I

\footnotetext{
2“Mi papa falleció antes de venir yo para acá Además yo era la nena linda de mi papa, supongo. Que me dolió mucho su partida y... en verdad lo que me hizo...que me cortara. Creo que es, en verdad que me sentía muy sola."
} 
don't love you, get lost, I don't want to see you here in my life.' My mother said, 'You should never have existed in my life."”3

Another source that some girls revealed was of having been physically and/or sexually abused $(n=11)$. One girl reflected on a particularly devastating event during which her father beat her pregnant mother:

He punched her, the baby, like eight times in a row. And I got so scared that I got a butcher knife-I called the police for [my mom] cause she was crying, and I told them to come over right now before I lose it. So when they came, I went to the room to talk to my little sister, playing around with her. And she started crying too cause she got scared. In the case of sexual abuse, the abuse was usually committed by an extended family member, such as a cousin, uncle, or stepfather. In such instances, the girls rarely reported the event to their mothers for fear of causing a rift in the family. In other cases, a 13-year-old girl of mixed Dominican and Puerto Rican parentage told her mother, but felt that her cries for help were left ignored:

I was telling her because he started touching me around my chest area and I was telling her "I want to go home, I wanna go home." She started yelling at me. She was like "You're not coming home, you're not coming home." She wanted to start her summer with her husband or whatever. She was only worrying about herself. She didn't let me go home. Two nights after that, that's when it happened [attempted suicide with Tylenol with codeine].

In describing another instance in which she attempted by cutting with a razor blade, this Dominican-Puerto Rican girl said that cutting her arm “didn't hurt. It made me feel good. 'Cause I like seeing pain. Feeling pain and seeing somebody else in pain...I guess I was hurting my mom". This girl was also among others who had experienced a sexual assault, yet her mother ignored her pleas for help. She sought revenge through acts of self-harm. Girls who experienced abuse developed patterns of aggressive behavior toward their parents, expressing their anger for not having been protected. This anger often came out during suicide attempts. In other cases, girls' responded to the abuse with guilt, either because they interpreted their actions as a cause of the abuse or because they failed to stop the abuse. For example, one girl, after experiencing repeated sexual abuse by her stepfather, began to eat a rough, jagged, pumice stone in an effort to cleanse herself.

The home environment was not the only source within which patterns of distress could emerge. Numerous girls reported being repeatedly teased, bullied, or victimized at school $(n=7)$. Some girls resorted to carrying weapons, such a razor blades or knives, for fear of being "jumped" in or after school:

This girl at school, she decided that she doesn't like me cause she doesn't like my attitude, something like that. So she was getting this group of girls together to jump me or whatever. And I was just like, alright, whatever. I always carry a weapon, always. So I don't really get scared. [12-year-old, Dominican, cut with razor blade] Other girls felt powerless or angry because they were unable to stop the bullying at school. Redirecting their emotions towards their body, some girls imagined killing the offending students while attempting suicide.

\footnotetext{
3“Mi mama cuando se enoja me dice 'no te quiero ver, te odio, te odio, no te quiero, largate, no te quiero ver aqui en mi vida'. Mi mama dijo 'no hubieras nunca que no hubieras existido en mi vida."”
} 


\section{Girls' Reflections: Reactions, Regrets and Insights}

The time period following the suicide attempt was characterized by an array of responses, reflections, and changes. Girls' immediate reactions to the attempt appeared to be influenced by the severity of the physiological response to the attempt. For some, daily life proceeded as usual. After attempting and feeling relief, they watched television, wrote poetry or did artwork, and went to sleep. Some felt immediate fear about what they had done (e.g., "What did I do; I just tried to kill myself") and told their family members, peers, or school teachers or counselors. Other times, girls' attempts were discovered by family members, either because the cuts were visible or the girl appeared to be acting strangely (e.g., sleepy, dazed, or agitated). In these latter instances, the paramedics were usually contacted.

In this group of Latinas, personal insights emerged in the aftermath of the suicide attempt. Insights about themselves and what they had done was accompanied with regret or puzzlement. A number of girls expressed regret about their actions. Regret was often articulated in the feeling that they were going to be forever marked as "crazy" for their actions. As one girl remarked, "I should have stopped the first time that I did that. I didn't want to go through what I went through. Like go to the hospital. Because it is for mental people, I felt like embarrassed" (15-year-old Mexican, cut herself with a safety pin). Some worried that the attempt would affect their future, that they may not be able to get jobs or that it will impact their future children. One attempter worried that "when I grow up, my children are going to see it. They are going to ask me why, why is that there. And I'm going to end up having to tell them, and it's like setting a bad example" (15-year-old, Ecuadoran, cut herself with broken glass).

For other girls, their experience in the mental healthcare system has been discovered by their peers, and the bullying and teasing at school persisted. Classmates called them "loony," "psycho," or "crazy." For one young girl, the very thing that shaped her decision to hurt herself —being teased at school—continued. She had cut herself to "get them [the students] to stop laughing at me, but I wasn't thinking at the time. I was just like just go right ahead and try to get your feelings out, and I did. I regret it every second of the day" (11-year-old, Puerto Rican, cut with math compass).

Other girls, in reflecting on their suicide attempts, were better able to connect their patterns of distress with the attempt. One girl said, insightfully, that 'I've seen things that I shouldn't have seen. And like, when I was a child, when I was supposed to be a child, I was more of an adult, trying to, like, protect my brother and sister. And now, sometimes, when I'm supposed to be an adult and mature, I act like a child" (17-year-old, Ecuadoran, cut with razor blade; emphasis added).

And for a few girls, the suicide attempt appears to have broken their patterns of distress. The attempt has led some girls to realize that "there are people who care, because a lot of people wanna help me" (14-year-old, Venezuelan, overdose on Tylenol). The attempt, in some ways, has brought some families together, and it has opened up channels of communication that were previously shut down. Sometimes, this improvement is felt immediately. For others, progress was slower, but it is still considered progress. The 13-year-old Dominican-Puerto girl hospitalized for an overdose on acetaminophen with codeine noted that her relationship with her mother is still "not beautiful, but it's getting better."

\section{Discussion}

Twenty-seven adolescent Latinas spoke about their suicide attempts. We analyzed the girls' interviews to answer our three research questions: What are the conditions in which suicide attempts occur among young Latinas? How do Latinas experience the circumstances that led 
to the attempt? What do the young women say precipitated their suicide attempts and what triggers the act?

The suicide attempts were grouped equally between girls who expressed intent to die (group 1) and girls who did not intend to die (group 2). In nearly all cases, the suicide attempts were self-injurious acts. (Two girls comprising a third group were uncertain about their intent and we could therefore not ascertain their motivation.) In all cases, the means of the attempt were non-lethal ingestions of medications or superficial self-cutting and met criteria for Type I and Type II suicide attempts (Silverman et al., 2007). Most of the suicide attempts were related to a pattern of distress, one of prolonged and intense conflict and rancor between the adolescent and her family. Parents were sometimes perceived as unable to understand the girl's pain or, worse, belittling her experiences of sexual abuse and trivializing her worries. Sometimes the conflict was with peers or the result of bullying and insults at school.

Those young Latinas who stated having an intent to die characterized themselves as depressed sad, lonely, guilt-ridden, worthless. Those who did not express a desire to die were more likely to be angry, frustrated, hateful, sad, stressed and confused. Although both groups of girls present worrisome profiles, those with a turning-in and self-blaming profile (group 1) appear to display the dysphoria, hopelessness and low self-efficacy that is associated with persistent depression. The angry-frustrated girls (group 2) seem to show less depression (although depressed, nonetheless) but with problems in regulating their emotions and channeling them appropriately.

Prominent across the girls in our study is a pattern of distress that each described and a trigger event described as occurring shortly or immediately before the suicide attempt, usually a heated argument with a parent, sibling or friend. However, the trigger event is not a singular incident or devoid of a context. We saw in the girls a number of ongoing worries and problems such as dramatic changes in family structure, conflict with parents and between parents, abuse, and bullying. Within a persisting pattern of instability, tension, conflicts, and victimization, the young Latina sensed herself as vulnerable. She may have felt misunderstood, not taken seriously, bereft of support and protection for others, and she could feel, too, violated physically, psychologically, and emotionally. At a particular moment in time, when the she was primed by the pattern to be in an emotionally fragile state, a trigger event reminded her of or revived the pain she carried through the ordeal of ongoing stress. In short, like combustion, kindling conditions had accumulated and a spark ignited the attempt.

Loneliness and a sense of alienation appear to play a major role in understanding the phenomenon of Latina suicide attempts. These girls feel that they cannot connect with someone who will understand what they are experiencing. The inability to have a connection with others is reflective of a broader cultural discontinuity within which these girls live: they belong neither to the culture of their parents nor to the broader culture into which they are inserted. Accounts of suicide attempts in other cultures, such as China (Biehl et al., 2007), Samoa (Macpherson \& Macpherson, 1987) and Japan (Traphagan, 2004), indicate how the influence of shifting cultural values is contributing to a powerful sense of alienation that raises the probability of suicides and suicide attempts. In this cross-cultural perspective, the suicide attempts may be construed as a response to the shifting roles of women-roles that are not yet consolidated but rather in flux, still imbued with societal and personal ambivalence. Accordingly, suicide attempts can be viewed as a social and personal response to the "the unmaking of time-honored value systems" (Biehl et al., 2007, p. 3) that have been so important to peoples' sense of stability and security.

Our cases are distinct from those of Trautman and Herrera et al. in interesting ways. Latinas in our sample are not made to feel marginal because western culture is infringing upon Hispanic 
values; the girls seem to understand this process. Rather, it is the extreme difficulty, possibly inability, to bridge the cultural discontinuity they see in two often contradictory value systems. They may feel the fracture between themselves and their families as they navigate two cultures. Along with the developmental push of adolescence toward greater autonomy comes the adoption of different definitions of self and womanhood that is placed before them by the mainstream culture. Both girls and parents may feel a distancing from each other, the fragmentation of family; familism seen as eroding as their daughters turn from traditional roles and adopt new ones. In some families young Latinas are able to bridge these two worlds that hold such strong emotional pulls. Some Latinas and their families seem to be less able to do so. In trying to cope with the fragmentation that this dilemma poses, often with little understanding or support from their families, the young women may resort to suicide attempts.

Altogether, these findings provide additional knowledge to the understanding of suicide attempts among adolescent girls of Hispanic origin or heritage in the U.S. There are limitations in the study that restrict generalizability. It was a small sample assessed qualitatively and without a complete psychiatric diagnostic research work-up. The Latinas in this group were recruited from New York City, a vast, densely populated urban environment in which the Hispanic population is primarily Dominican and Puerto Rican. The range of time that elapsed between the suicide attempt and the interview could have been up to six months, bringing into question the impact of memory and the accommodation of these recollections to new experiences and insights. The influence of psychotherapy cannot be overlooked since all girls were receiving or had received mental health services after the suicide attempts.

Notwithstanding these concerns, this study contributes to the understanding of the sociocultural context of suicide attempts by young Latinas, underscoring the cultural discontinuity they experience as they struggle to reconcile traditional Hispanic gender socialization with their own insertion in a modern Western society. Future research is needed to augment our knowledge. We need comparative studies that examine the suicidal experiences of nonHispanic adolescent girls. Exploring the meaning of the suicide attempt within and across cultures can make the link to motivating factors and why suicide attempts are the chosen forms for expression of emotional distress by ethnic and cultural affiliation. Moreover, such studies will have a major impact in shaping our understandings of the complexities of culture and the interplay between cultural contradictions and psychosocial well-being. Establishing how suicide attempts cluster within certain ethnic or socioeconomic groups promises insight into the links between culture, political economy, and individual experience.

\section{Acknowledgments}

Support for work on this paper was provided by NIMH grant R01MH070689. Heartfelt thanks are extended to Carolina Hausmann-Stabile, Jill Kuhlberg, and Allyson Pilat for their assistance in data collection and analysis.

\section{References}

Asencio MW. Machos and sluts: Gender, sexuality, and violence among a cohort of Puerto Rican adolescents. Medical Anthropology Quarterly 1999;13:107-126. [PubMed: 10322604]

Biehl, J.; Good, B.; Kleinman, A. Rethinking subjectivity. In: Biehl, J., et al., editors. Subjectivity: Ethnographic investigations. University of California Press; Berkeley, CA: 2007. p. 1-24.

Bordo, S. Unbearable weight: Feminism, western culture, and the body. University of California Press; Berkeley: 1993.

Bourgois, PI. In search of respect: Selling crack in el Barrio. Cambridge; New York: 2002.

Centers for Disease Control and Prevention. Suicide among children, adolescents, and young adultsUnited States, 1980-1992. Morbidity and Mortality Weekly Reports 1995;44:289-291.

Centers for Disease Control and Prevention. Youth risk behavior surveillance - United States, 2005. MMWR Surveillance Summary 2006;55(SS-5) 
Centers for Disease Control and Prevention. Youth risk behavior surveillance - United States, 2007. MMWR Surveillance Summary 2008;57(SS-4)

Chant, SH. Gender in a Changing Continent. In: Chant, SH.; Craski, N., editors. Gender in Latin America. Rutgers University Press; New Brunswick: 2003. p. 1-18.

Charmaz, K. Grounded theory. In: Smith, JA., editor. Qualitative psychology: A practical guide to research methods. Sage; Thousand Oaks, CA: 2003. p. 81-110.

Fortuna L, Perez JD, Canino G, Sribney W, Alegría M. Prevalence and correlates of lifetime suicidal ideation and suicide attempts among Latino subgroups in the United States. Journal of Clinical Psychiatry 2007;68:572-581. [PubMed: 17474813]

Garofalo R, Wolf C, Wissow LS, Woods ER, Goodman E. Sexual orientation and risk of suicide attempts among a representative sample of youth. Archives of Pediatric and Adolescent Medicine 1999; 153:487-493.

Garcia C, Skay C, Sieving R, Naughton S, Bearinger LH. Family and racial factors associated with suicide and emotional distress among Latino students. Journal of School Health 2008;78:487-495. [PubMed: 18786041]

Guttman, M. The meanings of macho: Being a man in Mexico City. University of California Press; Berkeley: 1996.

Herrera A, Dahlblom K, Dalgren L, Kullgren G. Pathways to suicidal behavior among adolescent girls in Nicaragua. Social Science \& Medicine 2006;62:805-814. [PubMed: 16098648]

Itzigsohn, J.; Dore-Cabral, C. The manifold character of panethnicity: Latino identities and practices among Dominicans in NY City. In: Laó-Montes, A.; Dávila, A., editors. Mambo montage: The Latinization of New York. University of Columbia Press; Columbia, NY: 2001.

Kao HS, McHugh ML, Travis SS. Psychometric tests of expectations of filial piety scale in a MexicanAmerican population. Journal of Clinical Nursing 2007;16:1460-1467. [PubMed: 17655534]

Kemper, EA.; Stringfield, S.; Teddlie, C. Mixed methods sampling strategies in social science research. In: Tashakkori, A.; Teddlie, C., editors. Handbook of mixed methods in social and behavioral research. Sage; Thousand Oaks, CA: 2003. p. 273-296.

LeBlanc, AN. Random family: Love, drugs, trouble and coming of age in the Bronx. Simon \& Schuster; New York: 2004.

Lester R. Critical therapeutics: Cultural politics and clinical relaity in two eating disorder treatment centers. Medical Anthropology Quarterly 2007;21:369-387. [PubMed: 18074903]

Maxwell JA. Understanding and validity in qualitative research. Harvard Educational Review 1992;62:279-299.

Moscicki EK, Crosby A. Epidemiology of attempted suicide in adolescents: Issues for prevention. Trends in Evidence-Based Neuropsychiatry 2003;5:36-44.

Nencel, L. Ethnography and Prostitution in Peru. Pluto Press; London: 2001.

O'Carroll PW, Berman AL, Maris RW, et al. Beyond the tower of babel: A nomenclature for suicidology. Suicide and Life-Threatening Behavior 1996;26:237-252. [PubMed: 8897663]

Ojito, M. Finding Mañana: A memoir of a Cuban exodus. Penguin; NY: 2005.

Patton, MQ. Qualitative evaluation and research methods. 2nd Ed.. Sage; Newbury Park, CA: 1990.

Rathus JH, Miller AL. Dialectical behavioral therapy adapted for suicidal adolescents. Suicide \& Life Threatening Behavior 2002;32:146-157. [PubMed: 12079031]

Razin AM, O'Dowd MA, Nathan A, Rodriguez I, Goldfield A, Martin C, Goulet L, Scheftel S, Mezan P, Mosca J. Suicidal behavior among inner-city Hispanic adolescent females. General Hospital Psychiatry 1991;13:45-58. [PubMed: 1993520]

Rew L, Thomas N, Horner S, Resnick MD, Beuhring T. Correlates of recent suicide attempts in a triethnic group of adolescents. Journal of Nursing Scholarship 2001;33:361-367. [PubMed: 11775307]

Silverman MM, Berman AL, Sanddal ND, O'Carroll PW, Joiner TE Jr. Rebuilding the Tower of Babel: A revised nomenclature for the study of suicide and suicidal behaviors Part 2: Suicide-related ideations, communications, and behaviors. Suicide and Life-Threatening Behavior 2007;37:264277. [PubMed: 17579539]

Smith, JA.; Osborn, M. Interpretative phenomenological analysis. In: Smith, JA., editor. Qualitative psychology: A practical guide to research methods. Sage; Thousand Oaks, CA: 2003. p. 51-80. 
Substance Abuse and Mental Health Services Administration (SAMHSA). Results from the 2002 National Survey on Drug Use and Health: National findings. Rockville, MD: 2003. Office of Applied Studies, NHSDA Series H-22, DHHS Publication No. SMA 03-3836

Taylor, JM.; Veloria, CN.; Verba, MC. Latina girls: "We're like sisters-Most times!”. In: Ross Leadbeater, BJ.; Way, N., editors. Urban girls revisited: Building strengths. New York University Press; New York: 2007. p. 157-174.

Tortolero SR, Roberts RE. Differences in nonfatal suicide behaviors among Mexican and European American Middle School Children. Suicide \& Life-Threatening Behavior 2001;31:214-223. [PubMed: 11459254]

Traphagan JW. Interpretations of elder suicide, stress, and dependency among rural Japanese. Ethnology 2004;43:315-329.

Trautman EC. The suicidal fit: A psychobiologic study on Puerto Rican immigrants. Archives of General Psychiatry 1961a;5:98-105.

Trautman EC. Suicide attempts of Puerto Rican immigrants. Psychiatric Quarterly 1961b;35:544-545. [PubMed: 13922318]

Turner S, Kaplan C, Zayas LH, Ross R. Suicide attempts by adolescent Latinas: An exploratory study of individual and family correlates. Child and Adolescent Social Work Journal 2002;19:357-374.

U.S. Census Bureau. U.S. Hispanic population surpasses 45 million: Now 15 percent of total. 2008a. http://www.census.gov

U.S. Census Bureau. Household income rises; poverty rate unchanged; number of uninsured down. 2008b. http://www.census.gov

Zayas LH, Bright C, Alvarez-Sanchez T, Cabassa LJ. Acculturation, familism and mother-daughter relations among suicidal and non-suicidal adolescent Latinas. Journal of Primary Prevention 2009;30:351-369. [PubMed: 19399622]

Zimmerman, JK. Crossing the desert alone: An etiological model of female adolescent suicidality. In: Gilligan, C.; Rogers, AG.; Tolman, DL., editors. Women, girls, and psychotherapy. Haworth Press; New York: 1991. p. 223-240.

Zimmerman, JK.; Zayas, LH. Suicidal adolescent Latinas: Culture, female development, and restoring the mother-daughter relationship. In: Canetto, S.; Lester, D., editors. Women and suicide. Springer; New York: 1995. p. 120-132. 


\section{Table 1}

Characteristics of study sample of suicidal adolescent Latinas sample $(\mathrm{N}=27)$

\begin{tabular}{lcccc}
\hline & $N$ & $\%$ & Mean & $S \boldsymbol{D}$ \\
\hline Age (Years) & & & 14.99 & 1.82 \\
Years of Education & & & 8.26 & 1.58 \\
U. S.-born & 20 & 74 & & \\
Self-identified Hispanic Group & & & & \\
$\quad$ Puerto Rican & 6 & 22 & & \\
$\quad$ Mexican & 5 & 18 & & \\
$\quad$ Dominican & 3 & 11 & & \\
$\quad$ Ecuadoran & 4 & 15 & & \\
$\quad$ Colombian & 3 & 11 & & \\
$\quad$ Honduran & 1 & 4 & & \\
$\quad$ Venezuelan & 1 & 4 & & \\
Other & 4 & 15 & & \\
Suicide Attempts & & & & \\
Cutting & 10 & 37 & & \\
Pill Ingestion & 6 & 22 & & \\
Multiple methods & 8 & 29 & \\
Other ${ }^{*}$ & 3 & 11 & \\
History of Previous Attempts & 21 & 77 & \\
\hline & & & & \\
& & &
\end{tabular}

Other = hanging, ingestion of household cleaners, jumping off a building 